\title{
Spell-Breaking with Revitalizing Metaphors
}

\begin{abstract}
Growing public interest in the dark arts, and the fact that even some philosophers have been accused of casting spells with their own writings, suggest that philosophers should not wholly neglect the topics of spells and spell-breaking. In this paper, written in honor of an effective spell-breaker in social and leadership contexts, Fr Theodore Vitali, I set out a taxonomy of spells and ways in which some philosophers may be said to cast them in a naturalistic sense. I also examine ways of breaking a spell, with reference to the will and second-person relationship. I conclude with a brief observation about the desire for intellectual completeness, the root of a disordered appeal of at least some spells to their victims, suggesting an alternative scenario for a good satisfaction of this desire.
\end{abstract}

\section{Introduction}

Associations of philosophy, spells and spell-breaking are sometimes forced upon us. As a doctoral student at St Louis University, 2006-2009, the connection for me often came about through my inability to navigate the peculiar split-level architecture of the Pius XII Memorial Library. Quite frequently, I emerged on what I thought was the upper level, full of sunlight streaming through the windows and the bright light of reason glorified in the works of great philosophers and theologians. Instead, I found myself on a gloomy lower level, somewhere 
between the integer floor numbers. ${ }^{1}$ Amid flickering fluorescent lights, the shelves were full of works on gnosticism, hermetic traditions, magic, spells, and witchcraft.

Whatever else may be said about these works, my abiding memory was the staggering number of volumes on the shelves and to the industry required to write them. People have obviously found the dark arts interesting, no doubt for a wide range of motivations, and they have written an awful lot about them. Moreover, this interest is scarcely a matter of an obscurantist and ignorant past, prior to the bright dawn of Cartesian reason and scientific method. For the most part, the volumes in the library were of fairly recent composition, consistent with other evidence of contemporary interest. ${ }^{2}$ Such evidence is readily available, from the 'spirituality' and 'metaphysics' sections of modern bookshops to the phenomenal sales of the Harry Potter books, set in a fictional England that is purged of any explicit references to Christianity and replete with magicians, magic, and strange creatures.

Professional philosophers today may, of course, have a certain equanimity about what the hoi polloi are reading, watching, and thinking. Only a part of the philosophical guild engages in theological issues, usually in a highly abstract fashion, and this part pays little attention to the dark side of what might, in a very broad sense, be called the 'spiritual.' By and large, such matters, which I shall henceforth label for convenience as the 'dark arts,' are simply filtered out of philosophical consideration even when the filters skew our perspective quite badly. Our usual knowledge of the Ancient Greeks, for example, has been sifted by both medieval Christian and

1 For fans of the Harry Potter books by British author J. K. Rowling, the notion of being on the non-integer floor of a split-level building may evoke the memory of the platform number for the train to Hogwarts.

2 As a passing commment, it should also be noted that the accounts we usually read of the rise of early modern science are the sanitised versions. A visit to the Royal Society in London and a perusal of the old bookshelves reveals a very eclectic range of interests, including some that would today be classified as occult. 
modern interests to focus on a small number of works by their most refined and rational thinkers. Only since the publication of E. R. Dodds, The Greeks and the Irrational (Dodds 1951) has there been some rediscovery of the darker, more irrational, and superstitious aspects of ancient Greek culture. Contemporary interests likewise filter out consideration of such matters. For example, at the time of writing, the entire Philosopher's Index of published works of the last twenty years has only a handful references to spell-breaking, all of which are figures of speech, with the most prominent being references to the title of a book by Daniel Dennett.

But are there not good reasons for avoiding such topics? The association of magic and spells with eclecticism and disordered reason do not suggest fertile territory for the contemplation of first principles, and many people who have worldviews that lack any objective referents for the term 'evil' will nevertheless regard the dark arts as distasteful fictions. Moreover, across a wide range of theological worldviews there are stern warnings to avoid such matters for moral and theological reasons. Spells and wizardry, with their focus on power, their moral ambiguity and sometimes explicit association with evil spirits, are strongly condemned in canonical Jewish and Christian Scriptures (e.g. Deuteronomy 18:10-14; Isaiah 47:12-14). By means of the Lord Elrond in The Lord of the Rings, J.R.R. Tolkien shares what may be a pertinent warning with his readers, "It is perilous to study too deeply the arts of the Enemy, for good or for ill" (Tolkien 1954, chap. II.2), hinting at moral dangers even for those studying the dark arts to oppose them. And C.S. Lewis, when he invented two devils, Screwtape and his nephew, for one of his most 
celebrated works, revealed that it had been a psychologically disturbing experience, even for the purposes of a story. ${ }^{3}$ So perhaps philosophers are wise to avoid the dark arts.

Nevertheless, I propose that there are at least some reasons why philosophers should not neglect such matters entirely. First, anyone who wants to nurture the intellectual virtues today needs to be aware of the competition for attention from a widespread and growing interest in the dark arts, a development that would perhaps be rather startling to futurists of the recent past. The relative decline of explicit Christian practice has not, on the whole, been accompanied by the rise of a scientistic society but one in which there is surprising ignorance of science and a strong interest in superstition and occult matters. Whatever the cause of these unexpected developments, there will probably be occasions when it is important to say something wise about them, and some prior philosophical consideration may therefore be prudent.

Second, the separation of matters associated with the dark arts and the works of philosophers may not always be as wide as it appears. Indeed, it may occasion some surprise that some writings by some influential philosophers have been compared to the dark arts themselves, suggesting a zone of overlap that deserves some critical attention. Consider, for example, the following words by Sir Isaiah Berlin, founder of Wolfson College, Oxford, and acclaimed as one of the finest minds of the twentieth century. In what follows, Berlin is making a comment on one of the most influential philosophers of recent centuries:

[His system] is a vast mythology which, like many other mythologies, has great powers of illumination as well as great powers of obscuring whatever it touches ... it

3 "The strain [of twisting one's mind into the diabolical] produced a sort of spiritual cramp. The world into which I had to project myself while I spoke through Screwtape was all dust, grit, thirst, and itch. Every trace of beauty, freshness and geniality had to be excluded. It almost smothered me before I was done” (C. S. Lewis 2017, 1). 
is like a very dark wood, and those who enter it very seldom come back to tell us what it is that they have seen. Or, when they do, like those who are addicted to the music of Wagner, their ear appears permanently attuned to sounds very unlike the older, simpler and nobler harmonies which once they used to listen to (Berlin 2002, 74).

Berlin's verdict seems to be that the system he describes is not an ordinary representation of the world that one evaluates objectively for its truth or falsity. The reference to the dark wood, an obvious allusion to the plight of Dante in the opening of the Divine Comedy, suggests something that can envelop and trap the unwary traveler in the manner of an evil enchantment. According to Berlin, even those who emerge to tell the world what they have seen have minds that are permanently changed, and it is clear that he does not consider this change wholesome.

Berlin's comments on another very famous philosopher, in the same book, are even more explicit:

You appear to be reading logical argument which distinguishes between concepts and draws conclusions in a valid manner from premises, when all the time something very violent is being said to you. A vision is being imposed on you; somebody is trying to dominate you by means of a very coherent, although often a very deranged, vision of life, to bind a spell [my italics], not to argue, despite the cool and collected way in which he appears to be talking (Berlin 2002, 43).

The verdict here, defended in the chapter, is that the philosopher in question casts a potent spell that can take away one's intellectual freedom. Indeed, the name of the book from which these observations are taken is Freedom and its Betrayal: Six Enemies of Human Liberty. 
In this paper, I do not assess the justice of Berlin's comments on these particular philosophers, but I am interested in Berlin's choice of metaphors. Whatever else may be said, he is asserting, in effect, that spells do not need to involve references to actual spiritual beings or forces or books of magic. On the contrary, even philosophers can write in ways that are appropriately described by metaphors of spells and enchantments. Indeed, Berlin warns, in effect, that some of these writings are so dangerous that they can warp the mind.

In this paper I explore the implications of Berlin's warnings and what can be learnt from them regarding the use and abuse of philosophy. My contribution is also intended to honor Fr Theodore Vitali. On more than one occasion, I have seen Fr Vitali defuse a potentially nasty situation or burst a little bubble of tension by means a down-to-earth image or anecdote; or humour; and even, on occasion, by recourse to non-monochromatic metaphors. On these occasions, cold tension was replaced by a relaxation and something resembling a return to life (indeed, Fr Vitali’s own name means 'life’ in Italian). Since Fr Vitali’s interventions bore some resemblance to stories of spell-breaking, it seems appropriate to devote this paper, in his honor, to the generally neglected philosophy of spells and spell-breaking.

\section{The Philosophy of Spells}

What is a spell? Attempts to answer this question philosophically immediately run into significant problems. My old Macmillan Encyclopedia of Philosophy (Edwards 1967) has no entry between 'Speculative Systems of History’ and 'Herbert Spencer,' suggesting a lack of interest or a denial that spells are a worthy subject for study. General dictionaries are also of limited utility, being more self-referential and circular than usual on the topic of spells. According to the Oxford English Dictionary, a spell, in the pertinent sense, is: 
A set of words, a formula or verse, supposed to possess occult or magical powers; a charm or incantation; a means of accomplishing enchantment or exorcism (“Spell, n.1” n.d.).

According to this definition, a spell typically involves some set of words ordered into a formula or verse and having the goal of enhancing power. ${ }^{4}$ But the definition also describes a spell in terms of an enchantment, which does not help much. Thomas Hobbes complains in Leviathan that "There is no place of Scripture, that telleth us what an Enchantment is" (Hobbes 2017, sec. III.37), and a definition is still hard to find. What, therefore, is a spell or an enchantment? Where does our understanding of being under a spell or an enchantment come from? How is it possible for Daniel Dennett to refer to "breaking a spell" with the expectation of being understood? And who has the philosophical and theological wisdom to provide insight into such matters?

The answer to the final question may furnish the answer to the others as well. There is, of course, an influential tradition of children's literature in modern Western culture, especially from the stories of Hans Christian Andersen and the vast compilations of European (especially German) folk literature by the Brothers Grimm in the nineteenth century. Many of these stories have medieval and ancient roots and include copious references to spells and spell-breaking. Most contemporary works, to the best of my belief, adopt and adapt the core ideas of these traditions. For convenience, I focus on two very influential stories of spells and spell-breaking from the Brothers Grimm and Andersen, respectively, and I add an episode from Dante's Inferno with similar structural features. All these works have multiple published versions, in many languages. I begin with brief summaries without commentary.

$4 \quad$ This meaning overlaps with other senses of the word 'spell,' such as reading by spelling out letters. 
First, in the story of Snow White, an evil queen consults her magic mirror to ask, "Who is the fairest in the land?" Upon learning that her stepdaughter, Snow White, is more beautiful than she is, she plans to kill her. After some failures, the queen succeeds in persuading Snow White to eat a piece of poisoned apple. She falls into a state of suspended animation and is assumed to be dead, being placed in a glass casket. But a prince travelling through the land sees her asleep and opens the casket. The piece of apple falls away and Snow White awakens.

Second, in the story of The Snow Queen by Hans Christian Andersen, a little boy called Kai has caught splinters in his eyes and in his heart. These splinters distort his perception and desires so that he admires only mathematical perfection and boasts of his rational knowledge. In this evil mood, the Snow Queen takes him to her palace. There he is left alone on a frozen lake, trying to form the word 'eternity' from blocks of ice, without which he can never leave. Fortunately for Kai, his childhood friend Gerda eventually finds him. Her tears wash the splinters out of his eyes and heart. He is able to recognise her, the blocks of ice arrange themselves into the word 'eternity,' and they are able to walk out of the palace.

Third, in Canto 10 of Dante's Inferno, Virgil accompanies Dante the traveler through the gates of the City of Dis into lower hell. They encounter first a huge cemetery of souls in burning tombs in which the heretics and their followers are imprisoned. These tombs lie unguarded and open until the Day of Judgment, when they will be sealed forever. As Dante passes the tomb of Epicurus and his followers, the soul of a countryman, Farinata, rises out of the tomb as far as the waist up. ${ }^{5}$ Farinata was an enemy to the party of Dante's ancestors but wishes to speak with him. As they are conversing, another soul, Cavalcante de' Cavalcanti, raises only his head above the

5 Epicurus, accused of denying the immortality of the soul, is the only heretic to be named explicitly. 
edge of the same tomb to see if his son is with Dante. When disappointed, he sinks back into the tomb.

What, then, is a spell? Drawing from these and similar tales, one can distill some rough principles of what it means to put someone under a spell as follows:

First, a spell forms a constricting trap, although the spell has no efficacious being before it is cast or after it is broken. Using the Aristotelian categories as a convenient taxonomy, such a trap narrows the possibilities of one or more of quantity, quality, relation, place, time, position, state, action or passion. For example, Snow White and the Dantean Epicureans are restricted to a casket or coffin and suspended from change. Kai is not constrained physically but his inability to solve a puzzle leaves him trapped in the palace of the Snow Queen, mesmorized by trying to form blocks of ice into the word 'eternity.' In this state, he is trapped in a small world in the manner of a mental casket or coffin. All these traps limit or sever relations with other persons.

Second, being placed under a spell involves distinct and deliberate acts by at least two persons: the spell-caster and the victim. This word 'cast' conveys suggestive connotations. Among its complex range of meanings, 'to cast' can mean: to project with a force, e.g. from the hand or from a military engine; to throw forth a net, fishing line, or a lure; to glance, especially with a desire to possess; to cause light or shadow to fall over a bounded region; to throw down or defeat; to convict, condemn, or throw in prison; to scheme; and to form something that is malleable into a rigid shape, as in casting metal. In the context of spell-casting, these connotations reinforce the notion of a trap fashioned to lure and imprison someone within a state that is open to entry but rigid and closed from the inside. But the victim also has to make some consenting act or omission of the will: Snow White has to eat the apple; Kai has to decide to go with the Snow Queen; and Dante’s Epicureans have to choose to follow their master. 
Third, once within the trap, there is a need for another person who is not under the spell to break the spell: this third person is actually or potentially a special 'you' to the victim, and the sequel to the rescue is some state of union, communion or friendship between the victim and the rescuer according to various "offices of love." ${ }^{6}$ Snow White is rescued by the prince, and Kai is rescued by his playmate Gerda. In the case of Dante’s Epicureans, Farinata and Cavalcante cannot be rescued: they are already in hell. But Dante adds a fascinating detail. They rise partly out of the tomb because of kinship: Farinata hears a countryman (10.22-33), and Cavalcante is looking for his son (10.52-54). The poem appears to suggest that the encounter with a special 'you' would be the key to breaking the spell of these Epicurians, if the spell was still breakable. ${ }^{7}$

Since Dante's hellscape is a finely graded abyss of increasing moral gravity, it is noteable that the placement of the Epicurean tomb also indicates Dante's view of where spell-casting should be placed on the moral landscape. There may be many reasons for one person to seek controlling power over another for the sake of the 'warm sins' of upper hell, such as anger or lust, or for some of the deeper 'cold sins' of lower hell (the City of Dis) such as fraud or betrayal. But Dante places this cemetery just inside the border of lower hell, situating it among the first of the cold sins, but no deeper. On this account, the choice of Epicurus as an emblematic figure at this point of the poem makes good sense. Epicurus represents tranquillity or equanimity with respect to both warm and cold sins and so plausibly represents spell-casting in a 'pure' form. This evil is of a very refined kind, the goal of which, when all other warm or cold sins are excluded as motivations, is a kind of dispassionate superiority over the victim.

$6 \quad$ For a discussion of "offices of love” see (Stump 2010, chap. 5). I use the term "second-person relatedness" as a shorthand phrase for the kind of relationship of 'I' to 'you'.

7 I note in passing that this interpretation is consistent with Eleonore Stump’s forthcoming book on the atonement. 


\section{Philosophical Spells and Spell-Breaking}

Having established some principles of spells in general, I turn next to the various ways in which a philosopher might be said to cast a spell, as Berlin claims, along with a few examples of spell-breaking techniques against these varieties. But how can that which is cast be called a 'spell'? I suggest the following to highlight some basic principles, starting with the consistent message of the great stories and mythologies that a spell forms a constricting trap.

Nothing-buttery spells. In a philosophical spell, one way to conceive of a trap is the placement of some artificial boundary around the kinds of answers that philosophers can give to questions of being. Sometimes this boundary is made explicit, especially in "nothing-buttery" statements or mantras added to commonly accepted accounts of reality to close off further enquiries. Such statements are common especially in reference to human beings, and some of these statements even enter popular culture from time to time. A song that was popular briefly in the 1990s had the line, "You and me, baby, ain’t nothing but mammals." ${ }^{8}$ This statement is a crude articulation of the more nuanced but very influential view that human distinctiveness is a matter of degree, not a different kind of thing. There are multitudes of similar nothing-buttery statements, such as that we not much more than water, or lucky apes, or gene machines, or meat machines, or assemblages of simple, deterministic atomic interactions and so on. Insofar as these statements aim to constrain the worldview of another person, one can call them nothing-buttery spells. ${ }^{9}$

8 (“Ain’t Nothing But Mammals Lyrics: The Bloodhound Gang - Absolute Lyrics” n.d.)

9 An early use of the phrase "nothing-buttery" is in a response to the claims that the brain is nothing but a machine (Pfeiffer 1955). 
Nothing-buttery spells are commonplace but also relatively fragile insofar as their claims are open to challenge by counterexamples. This opening leaves an opportunity for common sense to deliver a cognitive shock that may trigger a breakdown of the spell. As a miniature masterpiece of this spell-breaking technique, I quote at some length the following passage by G. K. Chesterton from The Everlasting Man.

In this text, Chesterton is dealing with the oft-cited claim that there is a continuity between human and animal construction, such as building nests and building houses. He writes in response,

For the very fact that birds do build nests is one of those similarities that sharpen the startling difference ... suppose our abstract onlooker saw one of the birds begin to build as men build. Suppose in an incredibly short space of time there were seven styles of architecture for one style of nest. Suppose the bird carefully selected forked twigs and pointed leaves to express the piercing piety of Gothic, but turned to broad foliage and black mud when he sought in a darker mood to call up the heavy columns of Bel and Ashtaroth; making his nest indeed one of the hanging gardens of Babylon. Suppose the bird made little clay statues of birds celebrated in letters or politics and stuck them up in front of the nest. Suppose that one bird out of a thousand birds began to do one of the thousand things that man bad already done even in the morning of the world; and we can be quite certain that the onlooker would not regard such a bird as a mere evolutionary variety of the other birds; he would regard it as a very fearful wildfowl indeed; possibly as a bird of ill-omen, certainly as an omen. That bird would tell the augurs, not of something that would happen, but of something that had happened. 
That something would be the appearance of a mind with a new dimension of depth; a mind like that of man (Chesterton 1925, chap. I.2).

Notice here how Chesterton shifts attention from the utilitarian and materialistic aspects of nestbuilding to the aesthetic ones, where the gap is stark between human and animal behaviour: birds do not build nests in the Gothic style or made statues of famous birds. More subtly, his unexpected turn and playful sense of humour diverts attention away from the representation of the world within the spell to the world itself. Having shocked the reader into this new vantage point, the nothing-buttery spell suddenly looks foolish and begins to lose its power.

Perfect infinite prisons. But what if one could cast a nothing-buttery spell without gaps? A spell of this kind, being seamless, would tend to be much more robust. I name this variation the "perfect infinite prison." What makes it a prison is that it has a nothing-buttery condition that sets a boundary to answers to questions of being; what makes it infinite is that there is no question, and perhaps no conceivable question within the domain of the trap, that the allowed range of philosophical answers within the trap cannot answer, albeit with a little ingenuity. To adopt the language of an earlier critique of these entrapping systems, they are non-falsifiable.

Very few such perfect spells have been devised in human history, but they have been potent in their impact on human lives and societies. An example in recent centuries is Marxism, which I count as a spell in the context of this paper because of its nothing-buttery materialism, and I count as a perfect infinite prison insofar as it is non-falsifiable (Popper 1963, 33-39).

Marxism is not one of the cruder materialisms, such as physicalism, and does not need them for its social goals, strictly speaking, even if it does not deny them. The focus and source of 
power for Marxism is instead on the prioritization of the mode of production of material life in conditioning all social, political and intellectual life (Marx 2014, chap. Preface).

The trick that makes the spell convincing, I think, is that as embodied and social creatures there is always some material and social aspect to what it is that we think or do or want to do. Hence with a little ingenuity, any question, and perhaps any conceivable question about human action and thought, can be given an answer in terms of the mode of production of material life and its concomitant social existence. Moreover, all these answers ultimately reduce to the same answer since, as Marx wrote, "It is not the consciousness of men that determines their existence, but their social existence that determines their consciousness” (ibid.). Marxist interpretations of events and history retain great influence, despite their limitations, perhaps because of the perennial and potent appeal of having an answer to every question.

How then does one fashion a remedy for a perfect, infinite prison which lacks gaps because it can illuminate anything, albeit with a monochrome tint? The only answers that I know involve telling better, brighter, and richer stories. From this larger perspective, once again, the spell can start to appear foolish and lose its power. As an example, when the historian Michael Burleigh wrote Sacred Causes in 2007, he wrote a history of the twentieth century that took a radically non-Marxist perspective, taking sacred causes seriously as large-scale, powerful motivations in world affairs (Burleigh 2007). Reading this book can come as refreshing shock. It provides a larger perspective on many familiar historical processes that have often been forced into the Procrustean bed of a Marxist interpretation in which ultimate causes are material. ${ }^{10}$

10 I note in passing that the Marxist forcing is not an intellectual game that is a victimless crime. From the perspective of Burleigh's analysis, for example, there are many contributing factors to the rise of evils that do not fit the Marxist framework easily and we risk forgetting such factors without better accounts of history. 
The tantalizing chronic noose. A third kind of spell suggests itself from situations in which one is presented with what looks like a coherent argument but is really the persuasive fragments of many arguments. These fragments generate mixtures of desirable and undesirable conclusions, along with the hint that the undesirable conclusions might be soluble if one employs another fragment in the same package. But as in the story of The Snow Queen, with Kay trying endlessly to form the word 'eternity' from blocks of ice, the puzzle is insoluble with the resources available. No matter how many fragments one tries, one cannot resolve all the problems, but one cannot let go of the puzzle. The whole vision is enticing and always on the verge of resolution, keeping one's attention fixed on an insoluble problem like the infinite loops or threshing of data in unresponsive computers. One might call this kind of a spell a tantalizing chronic noose. In the case of a computer, one often has to pull the plug. In the case of a human being, I think one often needs to give permission to stop, often by showing that not everything that looks intelligible is soluble, not all philosophers make sense, and one is not obliged to play the game.

I do not claim that this list of philosophical spells above is exhaustive, but it suffices to initiate a taxonomy and to exemplify the main principles. ${ }^{11}$ Drawing the elements of the nothingbuttery spell, the perfect infinite prison, and the tantalizing chronic noose together, what makes these traps enticing and how are they broken?

As noted previously, a spell forms a constricting and enclosed trap. From the outside the trap is foolish and dangerous, but not from the inside. If nothing else, a spell conveys a sense of completeness (or something that seems to tremble on the verge of completeness in the case of the tantalizing chronic noose). This completeness is attractive because the human mind enjoys

11 Eric Silverman, in his generous reply to an earlier draft of this paper, proposed further varieties of philosophical spell-casting, but the list I have given here is sufficient to illustrate the main principles. 
seeing things fit together and make apparent sense, like the joyful "Eureka!” of Archimedes solving the problem in his bath of measuring the density of a gold crown.

What makes a philosophical trap enticing, I think, is that it offers a vast range of apparent insights all at once. The cleverer versions even offer insights into everything, or at least all particulars within the domain of the trap. One might describe this bait as an intellectual counterpart to what Bonhoeffer called "cheap grace” (Bonhoeffer 1959): a satisfaction of the faculty of understanding that is far reaching, that requires little effort, and can even feed a sense of pride over those who do not share the vision. As long as one attends only to aspects of reality that filter into the representations of the trap, this understanding can also seem complete, albeit with the completeness of the inside of a coffin.

Also noted previously, it is invariably other persons who help us escape from such traps, an action of mercy that is ultimately an exercise of love. Logic alone is not enough because logic operating within the domain of the trap can at best demonstrate insufficiency or incoherence. The successful philosophical spell-breaker manages to communicate some understanding beyond the closed representation of the trap, revealing or reminding the victim of a bigger world. ${ }^{12}$ This understanding, being at variance with the domain of the trap, can trigger a collapse of the spell if the victim ceases to will the spell to be the self-sufficient and complete respresentation of all reality. ${ }^{13}$ This communication is where revitalising metaphors play a wholesome role, because a revitalising metaphor can evoke lived experiences that do not fit naturally or comfortably within

12 C. S. Lewis describes a process very vividly in his novel, That Hideous Strength (C. S. (Clive S. Lewis 1945, chap. 14). In the story, a young academic is being subjected to an evil initiation to instill in his mind a permanently warped representation of the world. But the process is impeded by numerous memories of experiences of the "Normal".

13 For the notion of “ceasing to resist” or quiescence of the will see also Aquinas (Stump 2003, 393-402). 
the spell's representation of reality. Laughter is also helpful, because pride is involved in maintaining the trap, and laughing at the absurdity of it is a way of breaking pride in a wholesome way. Hence evocative stories, short anecdotes, jokes, and perhaps also nonmonochromatic metaphors can all be ways of breaking through the spell.

But most important, the love shown by the spell-breaker is also crucial and may, in the end, be decisive. In the parable of The Snow Queen, the little girl Gerda cries over Kai and the tears melt the splinters in his eye and his heart. If what is needed is to stop willing the spell, and to cease to resist grace, then it may be the love of a second person that succeeds even if everything else fails.

\section{A Final Question:}

\section{Where Is Intellectual Completeness Found?}

Given that the bait of a philosophical spell is completeness, which is intellectually desirable, but the closure of a spell is a trap, is the desire for completeness doomed to frustration? We desire naturally to know, but the 'knowing' that counts ultimately is complete understanding. But what completeness is there that is not finished, closed, and dead? This question is a deep one and I sketch out here a few final thoughts regarding an outline of an answer.

When Thomas Aquinas describes truth, he describes it as an adaequatio or fitting of intellectus to some real thing, with intellectus often translated as understanding (de Veritate, 1.1). There is a proper joy in attaining harmony between the understanding and what is understood, but there is also a problem: this joy is transitory since there is always more to understand.

The seductive trick played by the philosophical spells is the implicit offer to complete this quest in a way that leaves nothing more to understand. But even apart from their limitations, 
these completions are finished, closed and dead. Just as Psalm 134 (135) warns that the makers of idols become like them, those who accept these offers ultimately become closed and dead as well.

But intellectus is not only a classical intellectual faculty but is also, in philosophical theology, a gift of the Holy Spirit (Pinsent 2012, chap. 2). When Aquinas illustrates this gift, he cites the example of the risen Christ walking beside the disciples on the road to Emmaus, explaining the Scriptures (ST II-II.8.2 sc; Luke 24:13-34). And the Scriptures of the New Testament, when describing this episode, bring a detail to our attention. The disciples say that their hearts burned within them as they walked with Christ (Luke 24:32).

I interpret this detail as follows. When disciples are walking beside Christ, they cannot be said to have understood everything and they are, no doubt, constantly gaining new insights. But despite the open-endedness of their unfinished discoveries, they do enjoy a sense of completeness due to the presence of their companion, illustrated by the metaphor of burning hearts. This completion is not a harmonization of subject with object but subject with coattending subject. In other words, this mysterious joy of the disciples does not have as its source a correspondence of their understanding with any or all particular intelligible things, as would be the case in the prideful and lonely completeness of a false representation. Rather their joy comes from the harmony of their open and illimitable understanding with the one who walks beside them. ${ }^{14}$

14 I am grateful to Eric Silverman for his response to an earlier draft of this paper, and to the staff and faculty members of the Department of Philosophy at St Louis University for their hospitality and support. 
Bibliography

“Ain’t Nothing But Mammals Lyrics: The Bloodhound Gang - Absolute Lyrics.” n.d. Accessed February 7, 2018.

http://www.absolutelyrics.com/lyrics/view/the_bloodhound_gang/ain’t_nothing_but_ma mmals/.

Isaiah Berlin. 2002. Freedom and Its Betrayal: Six Enemies of Human Liberty. Edited by Henry Hardy. First Edition. Princeton: Chatto \& Windus.

Dietrich Bonhoeffer. 1959. The Cost of Discipleship. Complete ed. / [translated from the German by R.H. Fuller, with Some revision by Irmgard Booth]. London: SCM.

Michael Burleigh. 2007. Sacred Causes: The Clash of Religion and Politics, from the Great War to the War on Terror. First Edition edition. New York: Harper.

Gilbert Keith Chesterton. 1925. The Everlasting Man. London: Hodder \& Stoughton.

Eric Robertson Dodds. 1951. The Greeks and the Irrational. Sather Classical Lectures; v. 25.

Berkeley; London: University of California Press.

Paul Edwards. 1967. The Encyclopedia of Philosophy. New York: London: Macmillan; CollierMacMillan.

Thomas Hobbes. 2017. Leviathan. New edition / introduction by Christopher Brooke. London: Penguin Classics.

Clive Staples Lewis. 2017. Screwtape Proposes a Toast. William Collins.

- 1945. That Hideous Strength: A Modern Fairy-Tale for Grown-Ups. London: Bodley Head.

Karl Marx. 2014. A Contribution to the Critique of Political Economy. Translated by N. I. Stone. Echo Library edition. Fairford: Echo Library. 
John E. Pfeiffer 1955. The Human Brain. [1st ed.]. New York: Harper.

Andrew Pinsent. 2012. The Second-Person Perspective in Aquinas's Ethics: Virtues and Gifts.

New York; Abingdon, UK: Routledge.

Karl Raimund Popper. 1963. Conjectures and Refutations: The Growth of Scientific Knowledge. London: Routledge \& Kegan Paul.

“Spell, n.1.” n.d. OED Online. Oxford University Press. Accessed February 7, 2018. http://www.oed.com/view/Entry/186214.

Eleonore Stump. 2003. Aquinas. London: Routledge.

— 2010. Wandering in Darkness: Narrative and the Problem of Suffering. Oxford: Clarendon Press.

John Ronald Reuel Tolkien. 1954. The Fellowship of the Ring. Oxford: George Allen \& Unwin. 